\title{
Adaptive Finite Element Mesh Generation for Dynamic Planar Problems
}

\author{
Yoon, Chongyul*
}

\begin{abstract}
In structural design and analysis used for hazard mitigation systems, automation is becoming an essential feature. For analysis, the finite element method has proven to be an effective approximate method if proper element types and meshes are chosen. Recently, the method has been successfully applied to solve complex dynamic and nonlinear problems; and with a properly chosen element type and mesh, reliable results have been obtained. However, in automation and in complex analyses of a structures, using the initial mesh throughout the analysis may involve some elements to go through strains beyond the elements' reliable limits. Thus, the finite element mesh for these types of analyses must be dynamically adaptive, and considering the rapid process of analysis in real time, the dynamically adaptive finite element mesh generating schemes must be computationally efficient. In this paper, a computationally efficient dynamically adaptive finite element mesh generation scheme for dynamic analyses of planar problems is described. The concept of representative strain value is used for error estimates and the refinements of meshes use combinations of the h-method (node movement) and the r-method (element division). A coefficient that depends on shape of elements is used to correct overly distorted elements. The validity of the scheme is shown by a deep cantilever beam example under a dynamic concentrated load. The example shows reasonable accuracy and efficient computing time. Furthermore, the study shows the potential for the scheme's effective use in complex structural problems such as those under severe environmental hazards such as seismic or erratic wind loads.
\end{abstract}

Key words : Structural hazard mitigation, Structural engineering, Dynamically adaptive finite element mesh, Finite element method

\section{요 지}

구조물의 전산 방재시스템의 한 부분인 설계-해석은 자동화가 필수적이다. 구조해석법으로는 유한요소법이 가장 많이 사용되 는 방법으로 자리 잡고 있으며, 근래에는 다소 복잡한 동적인 문제와 비선형 문제에도 사용이 일반화 되고 있다. 구조물을 유 한요소로 표현할 때 요소와 요소망이 적절히 선택되면 신뢰 있는 해석 결과를 출력한다. 그러나 구조물의 동적 또는 비선형 거동에는 예상하지 않은 부분에서 큰 변형이 일어날 수 있으며, 초기 요소망을 계속 사용하면 요소의 모양이 신뢰 있는 범위 에서 상당히 벗어 날 수 있으므로 요소망 역시 동적으로 적응할 필요가 있고, 실시간으로 빠르게 진행되는 해석 과정을 고려 하면, 동적인 적응적 유한 요소망 형성 전략은 연산면에서도 효율적이어야 한다. 본 연구는 시간영역 동적해석에서 전 단계 해 석 결과를 사용하여 계산된 대표 변형률 값을 오차 평가에 사용하고, 요소 세분화는 절점 이동인 $\mathrm{r}$-법과 요소 분할인 $\mathrm{h}$-법의 조합으로 계산하며, 모양계수 개념으로 과대하게 변형된 요소 모양을 방지하는 동적인 적응적 유한 요소망 형성 전략을 제시한 다. 적용한 캔틸레버 보의 예제를 통하여 정확성과 연산 효율성을 검증하였고 나아가 방법의 간단함이 지진 하중, 풍하중 등에 대한 해석이 필요한 방재 구조시스템의 복잡한 해석에도 효율적으로 사용될 수 있는 것을 보여 준다.

핵심용어 : 구조물 방재시스템, 구조공학, 동적인 적응적 유한요소망, 유한요소법

\section{Introduction}

In structural design and analysis used for hazard mitigation systems, automation is becoming an essential feature. For analysis, the finite element method (FEM) is proven to be an effective approximate method of structural analysis if proper element types and meshes are chosen (Bathe and Wilson, 1976; Belytschko et al., 1996; Cook et al., 1989; Reddy, 1993; Zienkiewcz et al., 2005). Recently, the method has been successfully applied to solve complex dynamic and nonlinear problems; and with a properly chosen element type and mesh, reliable results have been obtained. However, in automation and in complex analyses of a structure, using the initial mesh throughout the analysis may involve some elements to go through strains beyond the elements' reliable limits. Thus, the finite element mesh for these types of analyses must be dynamically adaptive, and considering the rapid process of analysis in real time, the dynamically adaptive finite element mesh generating schemes must be computationally efficient. When the method is applied to 
dynamics analyzed in the time domain, the meshes may need to be modified at each time step as the finite element results of an analysis largely depend on the mesh and the element types used (Heesom and Mahdjoubi, 2001; Jang and Lee, 2011; Yoon and Park, 2010).

In this paper, a dynamically adaptive finite element mesh generation scheme for dynamic analysis of structures is described. The adaptive mesh generation process involves estimation of error given a mesh and generation of a new improved mesh based on the error (Choi and Jung, 1998; Choi and Yu, 1998; de Las Casa, 1988; Zienkiewcz and Zhu, 1987). The dynamically adaptive scheme uses computationally simple error estimation based on representative strain. The mesh generating scheme combines the r-method (moving an existing node) and the h-method (dividing an element into smaller elements). The scheme includes a check for limiting distortion for each element using the concept of shape factor that is easily computed for each shape (Yoon, 2005). The dynamic analysis considered is in time domain, based on direct integration. As an example, an undamped deep cantilever beam modeled with four node quadrilateral isoparametric elements for plane stress is considered. The results of the analyses of the example show that the proposed dynamically adaptive finite element mesh scheme using the error estimation based on the representative strain, the $r-h$ method, and the shape factor is efficient computationally and have reasonable confidence level for complex dynamic problems in structural analysis.

\section{Adaptive Mesh Scheme for Dynamic Analysis}

\subsection{Error Estimation with Representative Strains}

The results of a finite element analysis largely depend on the type of element and the mesh used. An adaptive mesh generation scheme attempts to automate the mesh generation and in the scheme, accuracy of error estimation of a given mesh is essential (Hwang, 1988; Jeong et al., 2003; McFee and Giannacopoulos, 2001; Ohnimus et al., 2001; Stampfle et al., 2001; Yoon, 2005; Zhu et al., 1991). In general engineering problems, accurate solutions are not known and thus accurate error estimation is inherently a difficult problem. In addition, error estimation for adaptive mesh needs to be computationally efficient, especially for dynamic problems, since there are extensive additional computations needed for many aspects of adaptive mesh generation and analyses that follow. Norm of a matrix is generally used to represent error of a mesh where the matrix includes values of stress, strain and displacements. Norm of error $\|E\|$ in the domain $\Omega$ may be represented as follows:

$$
\|E\|=\left[\int_{\Omega}(\varepsilon-\hat{\varepsilon})^{T}(\sigma-\hat{\sigma}) d \Omega\right]
$$

Here $\sigma, \varepsilon$ are the exact solutions for stress and strain and $\hat{\sigma}, \hat{\varepsilon}$ are the finite element solutions. The error defined in Eqs. (2-5) are the representative strains of element based on the standard deviations of the strains at the Gauss points in the element computed during the previous finite element analysis (Jeong and Yoon, 2003; Yoon, 2009). The $z$ axis is not considered in $x-y$ planar problems, and the representative strain values of element $i$ are represented by the following equations:

$$
\begin{aligned}
& \|e\|_{i x}=\sqrt{\frac{\sum_{j=1}^{n_{g x}}\left(\varepsilon_{j x}-\varepsilon_{x}^{*}\right)^{2}}{n_{g x}-1}} \\
& \|e\|_{i y}=\sqrt{\frac{\sum_{j=1}^{n_{g y}}\left(\varepsilon_{j y}-\varepsilon_{y}^{*}\right)^{2}}{n_{g y}-1}} \\
& \|e\|_{i x y}=\sqrt{\frac{\sum_{j=1}^{n_{g x y}}\left(\gamma_{j x y}-\gamma_{x y}^{*}\right)^{2}}{n_{g x y}-1}} \\
& \|e\|_{i}=\left\{\|e\|_{i x}+\|e\|_{i y}+\|e\|_{i x y}\right\} \times \frac{A_{i}}{A_{\text {total }}}
\end{aligned}
$$

Here, $\|e\|_{i x}$ is the $\mathrm{x}$ directional standard deviation of the strain, $n_{g x}$ is the number of Gauss points in $\mathrm{x}$ direction, $\varepsilon_{j x}$ is the $\mathrm{x}$ directional strain of Gauss point $j$, and $\varepsilon_{x}^{*}$ is the $\mathrm{x}$ directional strain; $\|e\|_{i y}, n_{g y}, \varepsilon_{j y}, \varepsilon_{y}^{*}$ are the similar y directional values and $\|e\|_{i x y}, n_{g x y}, \gamma_{j x y}, \gamma_{x y}^{*}$ are the similar $\mathrm{x}-\mathrm{y}$ shear strain values. In addition, $A_{i}$ is the element area and $A_{\text {total }}$ is the total area of the mesh.

\subsection{Dynamic Analysis}

The direct numerical integration in the time domain is used for the dynamic analysis. Specifically, the Newmark- $\beta$ method, a reliable explicit method widely used in dynamic structural analysis, is used (Bathe and Wilson, 1976; Belytschko, 1974; Newmark, 1959). The equations in the Newmark- $\beta$ method may be summarized as follows:

$$
\begin{aligned}
& \dot{u}_{i+1}=\dot{u}_{i}+(\Delta t)\left[(1-\gamma) \ddot{u}_{i}+\gamma \ddot{u}_{i+1}\right] \\
& u_{i+1}=u_{i}+(\Delta t) \dot{u}_{i}+(\Delta t)^{2}\left[\left(\frac{1}{2}-\beta\right) \ddot{u}_{i}+\beta \ddot{u}_{i+1}\right]
\end{aligned}
$$

Here, $u_{i}, \dot{u}_{i}, \ddot{u}_{i}$ are the displacement, velocity, and acceleration vectors in the $i$ th step and $u_{i+1}, \dot{u}_{i+1}, \ddot{u}_{i+1}$ are the similar quantities in the $i+1$ th step; $\Delta t$ is the time step length; $\beta$ and $\gamma$ are parameters selected by the user and the recommended values of $\beta=1 / 4$ and $\gamma=1 / 2$ are used.

The matrix equilibrium equations for the $i$ th step may be represented as follows:

$$
K^{\prime} u_{i+1}=F_{i+1}^{\prime}
$$

The matrices $K^{\prime}$ and $F^{\prime}{ }_{i+1}$ represent the following: 


$$
\begin{aligned}
& K^{\prime}=K+\frac{1}{\beta(\Delta t)^{2}} M \\
& F^{\prime}{ }_{i+1}=F_{i+1}+\frac{M}{\beta(\Delta t)^{2}}\left[u_{i}+(\Delta t)^{2} \dot{u}_{i}+\left(\frac{1}{2}-\beta\right)(\Delta t)^{2} \ddot{u}_{i}\right]
\end{aligned}
$$

Here, $K$ is the stiffness matrix, $M$ is the mass matrix, and $F_{i+1}$ is the force vector for the $i+1$ th time step.

\subsection{Adaptive Mesh Generation Scheme}

The adaptive mesh generation based on the error estimation with representative strains is formulated combining the r-method and the h-method. The r-method moves existing nodes based on the following equations for the new coordinates $x_{b}, y_{b}$ :

$$
\begin{gathered}
x_{b}=\frac{\sum_{i=1}^{n_{m}} x_{c i}\left(\|e\|_{i}\right)}{\sum_{i=1}^{n_{m}}\left(\|e\|_{i}\right)} \\
y_{b}=\frac{\sum_{i=1}^{n_{m}} y_{c i}\left(\|e\|_{i}\right)}{\sum_{i=1}^{n_{m}}\left(\|e\|_{i}\right)}
\end{gathered}
$$

Here, $x_{c i}, y_{c i}$ are the coordinates of the centroid of the element, $n_{m}$ is the number of elements and $\|e\|_{i}$ is the representative strain value of the element $i$. Eq. (11) and Eq. (12) for nodes on the boundary are modified according to the following equations:

$$
\begin{gathered}
x_{b}=\frac{\sum_{i=1}^{2} x_{l c i}\left(\|e\|_{i}\right)}{\sum_{i=1}^{2}\left(\|e\|_{i}\right)} \\
y_{b}=\frac{\sum_{i=1}^{2} y_{l c i}\left(\|e\|_{i}\right)}{\sum_{i=1}^{2}\left(\|e\|_{i}\right)}
\end{gathered}
$$

Here, $x_{l c i}, y_{l c i}$ are the $\mathrm{x}, \mathrm{y}$ coordinates of the central point on the boundary. A further attempt to keep the elements rectangular, and width to depth ratio to be close to 1 are maintained. A concept of shape factor defined in Eq. (15) and described in detail in reference Yoon (2009) is used to limit distortion of elements.

$$
\text { ShapeFactor }=\frac{\sqrt{A_{i}}}{0.25 L_{t i}}
$$

Here, $L_{t i}$ is the length of the boundary of the element. The shape factor is 1 for square and an attempt to keep shape factor to be close to 1 is maintained; shapes with a shape factor less than 0.90 are not recommended.

The h-method divides an element into smaller elements of the same type. The elements to be subdivided are based on the discretization parameter $d$ :

$$
d=\alpha \times \text { mean }\left[\|e\|_{\text {initial }}\right] \div \max P
$$

Here, $\alpha$ is a constant, mean $\left[\|e\|_{\text {initial }}\right]$ is the average representative strain value of the initial mesh and $\max P$ is the maximum value of the applied load. A parametric study suggests a value between 12.0 and 15.0 to be used for $\alpha$.

The r-h method combines r-method and h-method. Various means of combining have been studied (de Las Casas, 1988; Hwang, 1988; Yoon, 2005). To obtain an optimal combination of r-method and h-method, first the representative strain values are normalized at each step using the following equations.

$$
\begin{aligned}
& \min \left[\|e\|_{i}\right] \times a+b=0 \\
& \max \left[\|e\|_{i}\right] \times a+b=100
\end{aligned}
$$

Here, $\min \left[\|e\|_{i}\right], \max \left[\|e\|_{i}\right]$ are the minimum and maximum values of the representative strains, and $a, b$ are constants in each step determined from Eq. (17) and Eq. (18). These two equations are used to normalize the representative strains to range from 0 to 100 .

A dispersion parameter $\mathrm{Cr}$ is defined as follows:

$$
C r=\left|M_{e}-M_{o}\right|
$$

Here, $M_{e}$ is the average of the normalized representative strains and $M_{o}$ is the mode of distribution of the representative strain values. A value for $\mathrm{Cr}$ needs to be set to combine the r-method and the h-method and a reasonable value is around 18 20 where if $\mathrm{Cr}$ is larger than this value, r-method is used, and in other cases, the h-method is used.

In the h-method, the refinement of the mesh is terminated when the change in the representative strain values is less than $1 \%$ or when the element's discretization parameter is less than $d$ in Eq. (16). In the r-method, the refinement of the mesh is terminated when the element's discretization parameter is less than $d$ in Eq. (16).

\section{A Deep Cantilever Beam Example}

The example considered is a $200 \mathrm{~cm}$ deep, $800 \mathrm{~cm}$ long cantilever beam. The beam is modeled with four node isoparametric quadrilateral plane stress elements. The dynamic loading is a lateral concentrated load $\mathrm{P}$ at the free end where between $\mathrm{t}=0$ and $\mathrm{t}=1$ second the function is given by the following equation (see Fig. 1):

$$
P=-500 \sin (2 \pi t)
$$

Free vibration response continues after the steady state response for 1 second, and the total response time considered is 5 seconds. A crude initial mesh formed by four equal elements arranged along the beam axis is used for the investigation. More appropriate initial mesh increases the effi- 


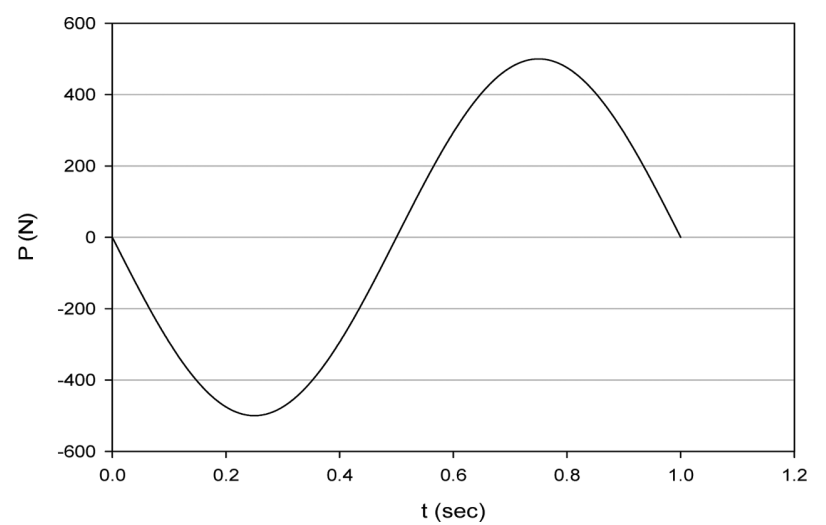

Fig. 1. Time variation of the Lateral Concentrated Load at the Free End

ciency of the algorithm.

The beam is $5 \mathrm{~cm}$ thick and the material obeys Hooke's law for elasticity with the modulus of elasticity of $210 \times 105$ $\mathrm{N} / \mathrm{cm}^{2}$ and Poisson's ratio of 0.3 . The unit mass is $7.85 \times 10^{-3}$ $\mathrm{kg} / \mathrm{cm}^{3}$. The time step selected for analysis is 0.034 seconds yielding 145 steps. For comparison purposes, solutions from a regularly discretized mesh of 1024 elements is termed the engineering solution, the ones from 216 elements is terms the general solution, and the solution from the converged

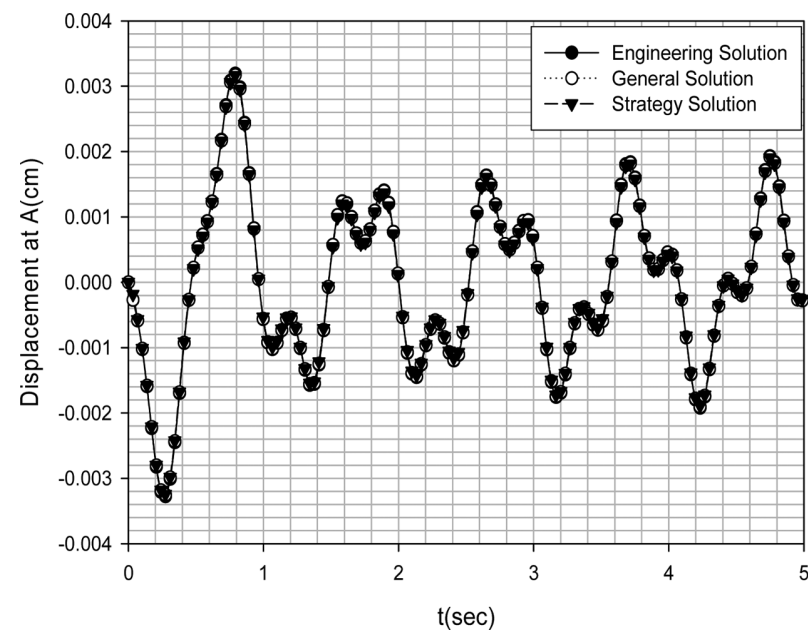

Fig. 2. Vertical displacement of the free end A

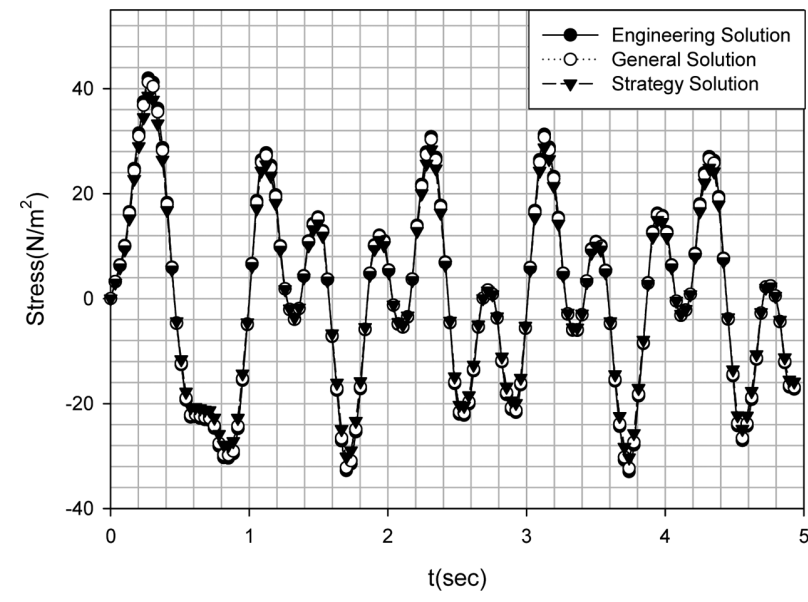

Fig. 3. Mid-horizontal normal stress at the fixed end adaptive mesh is termed the strategy solution. Fig. 2, Fig. 3 and Fig. 4 show respectively, the comparisons of the vertical displacement at $\mathrm{A}$ which is the free end, the mid-horizontal (x directional) normal stress at the fixed end, and the midvertical (y directional) normal stress at the fixed end of the engineering, the general, and the strategy solutions. The figures show close agreement among the three solutions.

Table 1 shows the representative strain values in the initial steps of the dynamic adaptive mesh where the transitions of the r-method and the h-method are shown. Fig. 5 shows the geometry of the deep beam example and Fig. 6 shows the 6 by 36 regularly discretized mesh of 216 elements used for the general solution. Fig. 7 shows some samples of the generated mesh during the analysis and Fig. 8 shows the mesh during the maximum deflection at the free end which is at 0.272 seconds, where the number of elements is 270 and the number of nodes is 318 .

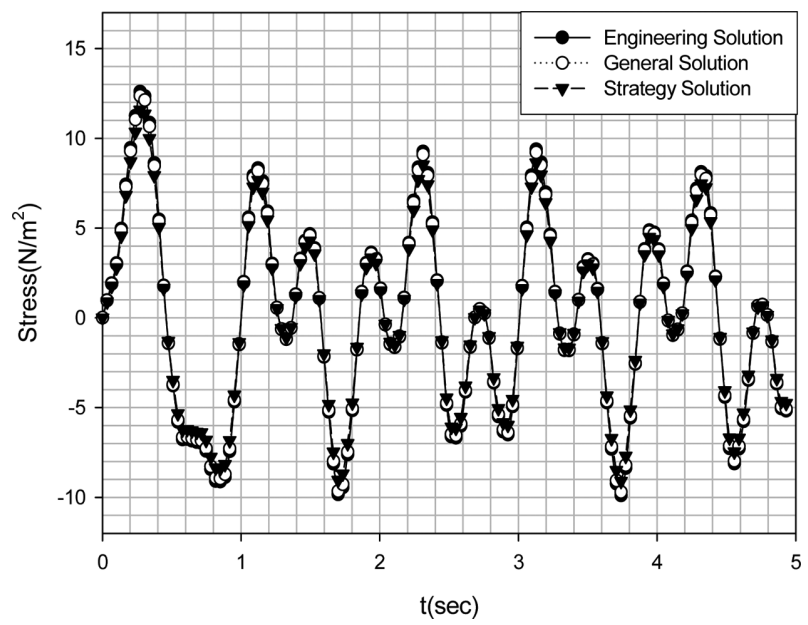

Fig. 4. Mid-vertical normal stress at the fixed end

Table 1. Representative strain values for the adaptive scheme

\begin{tabular}{|c|c|c|c|c|}
\hline Step & Method & $\begin{array}{c}\text { Maximum. } \\
\text { Representative } \\
\text { Strain (\%) }\end{array}$ & $\begin{array}{c}\text { Sum of } \\
\text { Representative } \\
\text { Strain (\%) }\end{array}$ & $\begin{array}{c}\text { Variation of } \\
\text { Representative } \\
\text { Strain (\%) }\end{array}$ \\
\hline 0 & & 0.0000292 & 0.0000649 & - \\
\hline 1 & $\mathrm{~h}$ & 0.0000051 & 0.0000436 & 32.82 \\
\hline 2 & $\mathrm{~h}$ & 0.0000010 & 0.0000253 & 41.97 \\
\hline 3 & $\mathrm{r}$ & 0.0000009 & 0.0000251 & 0.79 \\
\hline 4 & $\mathrm{r}$ & 0.0000008 & 0.0000250 & 0.39 \\
\hline 5 & $\mathrm{r}$ & 0.0000008 & 0.0000248 & 0.80 \\
\hline 6 & $\mathrm{~h}$ & 0.0000002 & 0.0000142 & 42.74 \\
\hline
\end{tabular}

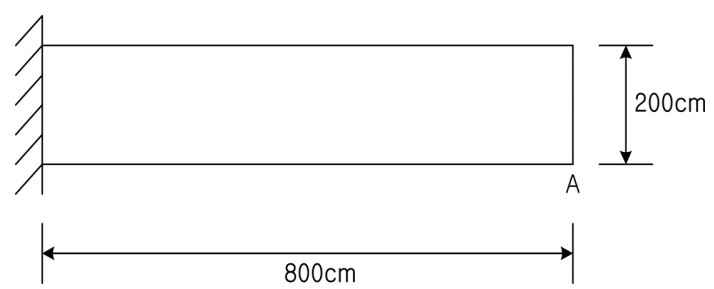

Fig. 5. Geometry of the deep cantilever beam example 


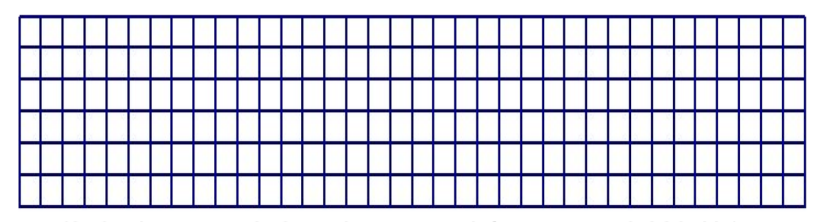

(216 elements, 259 nodes, natural frequency: $0.980 \mathrm{~Hz}$ )

Fig. 6. Regular Mesh used for the general solution

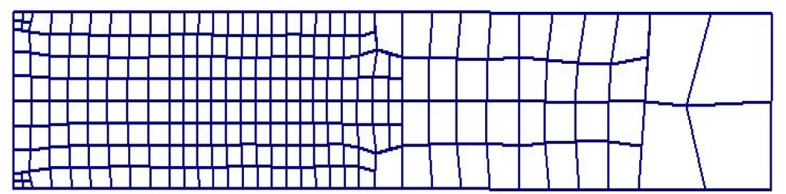

(a) $1.25 \mathrm{sec}$ (228 elements, 273 nodes, natural frequency: $0.967 \mathrm{~Hz}$ )

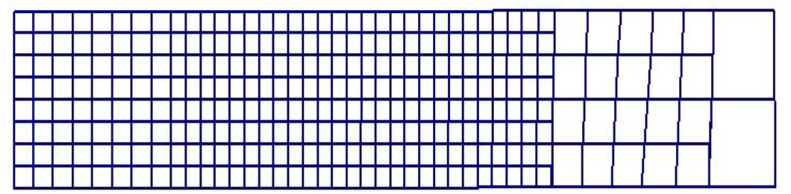

(b) $2.5 \mathrm{sec}$ (286 elements, 334 nodes, natural frequency: $0.960 \mathrm{~Hz}$ )

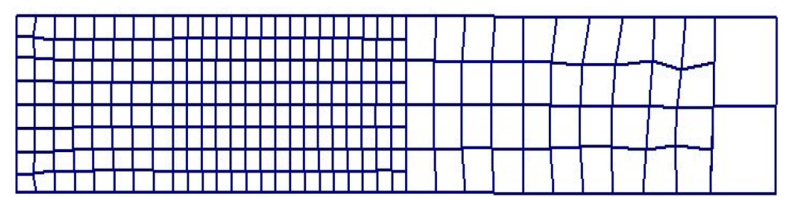

(c) $3.75 \mathrm{sec}$ (234 elements, 278 nodes, natural frequency: $0.973 \mathrm{~Hz}$ )

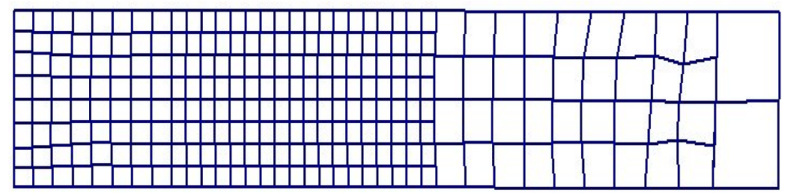

(d) $5 \mathrm{sec}$ (246 elements, 292 nodes, natural frequency: $0.979 \mathrm{~Hz}$ )

Fig. 7. Generated adaptive meshes during analysis

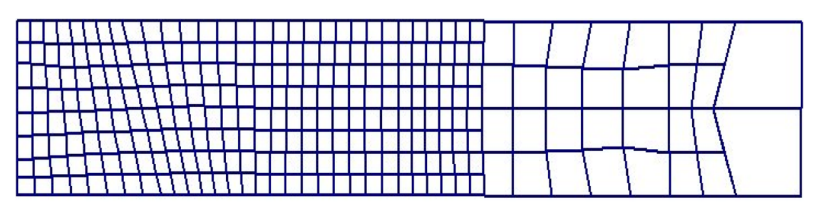

Maximum deflection at $0.272 \mathrm{sec}$

(270 elements, 318 nodes, natural frequency: $0.980 \mathrm{~Hz}$ )

Fig. 8. Mesh used at the maximum deflection at the free end

Note that at the boundary between the fine and the coarse meshes, the nodes at the middle of the coarse mesh is slaved to the end nodes for displacement compatibility.

Although the computing efficiency is continuously increasing in general, the enormous amount of computing needed in the complex analysis of structures requires computing efficiency in every aspect of the algorithm in order for the method to be practical (Ladeveze and Oden, 1998; MacLeod, 2002; Rafiz and Easterbrook, 2005). Table 2 shows the comparative computation times and error where it shows reasonable accuracy and extreme computational efficiency of the strategy solution when compared to the engineering solution; only $1.34 \%$ error increase for stress and $0.62 \%$ error increase for displacement with $2.22 \%$ of the computing time.
Table 2. Comparative computation times and error

\begin{tabular}{|c|c|c|c|}
\hline $\begin{array}{c}\text { Solution } \\
\text { Method }\end{array}$ & $\begin{array}{c}\text { Displacement } \\
\text { Error vs } \\
\text { Engineering (\%) }\end{array}$ & $\begin{array}{c}\text { Stress Error } \\
\text { vs } \\
\text { Engineering (\%) }\end{array}$ & $\begin{array}{c}\text { Analysis Time } \\
\text { (Reduction vs } \\
\text { Engineering in \%) }\end{array}$ \\
\hline Engineering & 0.00 & 0.00 & $\begin{array}{c}2 \mathrm{hrs} 1 \mathrm{~min} 23 \mathrm{sec} \\
(0.00)\end{array}$ \\
\hline General & 0.70 & 1.82 & $\begin{array}{c}3 \mathrm{~min} 47 \mathrm{sec} \\
(3.16)\end{array}$ \\
\hline Strategy & 0.62 & 1.34 & $\begin{array}{c}2 \mathrm{~min} 42 \mathrm{sec} \\
(2.22)\end{array}$ \\
\hline
\end{tabular}

\section{Conclusions}

A dynamically adaptive mesh generation scheme for dynamic analyses of structures in time domain is presented. The scheme uses representative strain values from each element computed from the previous time step for estimation of error and an efficient combination of the r-method and the h-method for mesh refinement. A coefficient that depends on shape of elements is used to correct overly distorted elements. Analysis of the application of the scheme to a deep cantilever beam example shows that the representative strain value for estimation of error gives reasonable relative error. Since the computational requirement is small, the scheme is computationally efficient and successfully achieves the objective of identifying relative errors among the previous elements. An efficient combination scheme combining the traditional r-method and the h-method is shown to be practical as checks for limiting distortions of elements are incorporated.

The proposed adaptive mesh algorithm is computationally efficient and thus the scheme has potential to be appropriate for real time computations of large complex structures under erratic time dependent loads such as earthquakes and turbulent winds, problems important in maintenance of structures and structural hazard mitigation. Some aspects of the scheme still need to be improved, one of which is the appropriate selection of the initial mesh that starts the algorithm; this may be achieved with an appropriate development of an expert system.

\section{Acknowledgments}

This work was supported by 2010 Hongik University Research Fund.

\section{References}

Bathe, K.J. and Wilson, E.L. (1976) Numerical Methods in Finite Element Analysis, Prentice Hall, Englewood Cliffs.

Belytschko, T. (1974) Transient Analysis. Structural Mechanics, Computer Programs, Surveys, Assessments, and Availability, 
Edited by Pilkey, W., Saczalski, K. and Schaeffer, H. University of Virginia Press, Charlottesville, Virginia, pp. 255-276.

Belytschko, T., Hughes, J.R., and Bathe, K.J. (1996) Finite Element Procedures. Prentice-Hall, Englewood Cliffs.

Choi, C. and Jung, H. (1998) Adaptive Mesh Generation for Dynamic Finite element Analysis, J. Korean Soc. of Civil Eng. (in Korean), Vol. 18, No. I-2, pp. 203-220.

Choi, C.K. and Yu, W.J. (1998) Adaptive Finite Element Wind Analysis with Mesh Refinement and Recovery (in Korean). Wind and Structures, Vol. 1, pp. 111-125.

Cook, R.D., Malkus, D.S., and Plesha, M.E. (1989) Concepts and Applications of Finite Element Analysis, 3rd Ed. John Wiley \& Sons, New York.

de Las Casas, E.B. (1988) $R$-H Mesh Improvement Algorithms for the Finite Element Method, Ph.D. Dissertation, Purdue University, West Lafayette.

Heesom, D. and Mahdjoubi, L. (2001) Effect of Grid Resolution and Terrain Characteristics on Data from DTM. J. Comp. in Civil Eng., ASCE, Vol. 15, No. 2, pp. 137-143.

Hwang, S.W. (1988) A Study on the r-h Method in the Finite Element Method, Master's Thesis(in Korean), Inha University, Inchon.

Jang, H. and Lee, J. (2011) Seismic Analysis of Chemical Pump Using Automatic Mesh Generation System, J. Comp. Struct. Eng. Inst. of Korea, Vol. 24, No. 6, pp. 685-690.

Jeong, Y.C. and Yoon, C. (2003) Representative Strain Value Based Adaptive Mesh Generation for Plane Stress. Hongik J. Science and Tech., Vol. 7, pp. 71-86.

Jeong, Y.C., Yoon, C., and Hong, S. (2003) Adaptive Mesh Generation Scheme for Planar problems using Representative Strain Values for Error (in Korean). Proc., Korean Soc. Comp. Structural Eng., Vol. 16, No. 2-31, pp. 403-409.

Ladeveze, P. and Oden, J.T., Editors. (1998) Advances in Adaptive Computational Methods in Mechanics Studies in Applied Mechanics 47, Elsevier, Oxford.

MacLeod, I.A. (2002) The Education of Structural Analyst. Proc., Asranet Symp., Asranet, Dept. of Naval Architecture and Marine Eng., Univ. of Glasgow and Strathclyde, London.

McFee, S. and Giannacopoulos, D. (2001) Optimal Discretizations in Adaptive Finite Element Electromagnetics. Int. J. Numer. Meth. Eng., Vol. 52, No. 9, pp. 939-978.

Newmark, N.M. (1959) A Method of Computation for Structural Dynamics. J. Eng. Mech. Division, American Society of Civil Engineers, Vol. 85, No. EM3, pp. 67-94.

Ohnimus, S., Stein, E., and Walhorn, E. (2001) Local Error Estimates of FEM for Displacements and Stresses in Linear Elasticity by Solving Local Neumann Problems. Int. J. Numer. Meth. Eng., Vol. 52, No. 7, pp. 727-746.

Rafiq, M.Y. and Easterbrook, D.J. (2005) Using the Computer to Develop a Better Understanding in Teaching Structural Engineering Behavior to Undergraduates. J. Comp. in Civil Eng., Vol. 19, No. 1, pp. 34-44.

Reddy, J.N. (1993) An Introduction to the Finite Element Method, 2nd E., McGraw-Hill, New York.

Stampfle, M., Hunt, K.J., and Kalkkuhl, J. (2001) Efficient Simulation of Parameter-Dependent Vehicle Dynamics. Int. J. Numer. Meth. Eng., Vol. 52, No. 11, pp. 1273-1299.

Yoon, C. (2005) Adaptive Mesh Generation for Dynamic Finite Element Analysis (in Korean). J. Korean Soc. Civil Eng., Vol. 25, No. 6A, pp. 989-998.

Yoon, C. (2009) Computer Aided Teaching of Structural Engineering Using Adaptive Schemes in the Finite Element Method. $J$. Korean Soc. Hazard Mitigation., Vol. 9, No. 1, pp. 9-13.

Yoon, C. and Park, J. (2010) Dynamically Adaptive Finite Element Mesh Generation Schemes, J. Comp. Struct. Eng. Inst. of Korea, Vol. 23, No. 6, pp. 659-665.

Zhu, J.Z., Zienkiewicz, O.C., Hinton, E., and Wu, J. (1991) A New Approach to the Development of Automatic Quadrilateral Mesh Generation. Int. J. Numer. Meth. Eng., Vol. 32, pp. 849-866.

Zienkiewicz, O.C., Taylor, R.L., and Zhu, J.Z. (2005) The Finite Element Method: Its Basis and Fundamentals, 6th Ed. Elsevier Butterworth-Heinemann, Oxford.

Zienkiewcz, O.C. and Zhu, J.Z. (1987) A Simple Error Estimator and Adaptive Procedure for Practical Engineering Analysis. Int. J. Numer. Meth. Eng., Vol. 24, pp. 337-357.

() 논문투고일 : 2012년 11월 09일 () 심사의뢰일 : 2012년 11월 12일 () 심사완료일 : 2012년 11월 21일 